\title{
A multicenter study confirms CD226 gene association with systemic sclerosis-related pulmonary fibrosis
}

Lara Bossini-Castillo ${ }^{1 *}$, Carmen P Simeon ${ }^{2}$, Lorenzo Beretta ${ }^{3}$, Jasper C Broen ${ }^{4}$, Madelon C Vonk ${ }^{4}$, Raquel Ríos-Fernández ${ }^{5}$, Gerard Espinosa ${ }^{6}$, Patricia Carreira ${ }^{7}$, María T Camps ${ }^{8}$, Maria J Castillo9 Miguel A González-Gay ${ }^{10}$, Emma Beltrán ${ }^{11}$, María del Carmen Freire ${ }^{12}$, Javier Narváez ${ }^{13}$, Carlos Tolosa ${ }^{14}$, Torsten Witte ${ }^{15}$, Alexander Kreuter ${ }^{16}$, Annemie J Schuerwegh ${ }^{17}$, Anna-Maria Hoffmann-Vold ${ }^{18}$, Roger Hesselstrand ${ }^{19}$, Claudio Lunardi ${ }^{20}$, Jacob M van Laar ${ }^{21}$, Meng May Chee ${ }^{22}$, Ariane Herrick ${ }^{23}$, Bobby PC Koeleman ${ }^{24}$, Christopher P Denton ${ }^{25}$, Carmen Fonseca ${ }^{25}$, Timothy RDJ Radstake ${ }^{26 \dagger}$ and Javier Martin ${ }^{1 \dagger}$, for the Spanish Scleroderma Group

\begin{abstract}
Introduction: CD226 genetic variants have been associated with a number of autoimmune diseases and recently with systemic sclerosis (SSc). The aim of this study was to test the influence of CD226 loci in SSc susceptibility, clinical phenotypes and autoantibody status in a large multicenter European population.

Methods: A total of seven European populations of Caucasian ancestry were included, comprising 2,131 patients with SSC and 3,966 healthy controls. Three CD226 single nucleotide polymorphisms (SNPs), rs763361, rs3479968 and rs727088, were genotyped using Taqman 5'allelic discrimination assays.

Results: Pooled analyses showed no evidence of association of the three SNPs, neither with the global disease nor with the analyzed subphenotypes. However, haplotype block analysis revealed a significant association for the TCG haplotype (SNP order: rs763361, rs34794968, rs727088) with lung fibrosis positive patients $\left(P_{\text {Bonf }}=3.18 \mathrm{E}-02\right.$ OR 1.27 (1.05 to 1.54$)$ ).

Conclusion: Our data suggest that the tested genetic variants do not individually influence SSc susceptibility but a CD226 three-variant haplotype is related with genetic predisposition to SSc-related pulmonary fibrosis.
\end{abstract}

\section{Introduction}

Systemic sclerosis (SSc) is a connective tissue disorder in which fibrotic collagen deposition, vascular damage, autoimmunity and autoantibody production (especially anticentromere (ACA), and antitopoisomerase, (ATA) antibodies) are the main hallmarks [1]. SSc patients can be classified classically in two major subgroups, those suffering from limited cutaneous SSc (lcSSc) and those with the diffuse cutaneous form of the disease (dcSSc) [2].

\footnotetext{
* Correspondence: larabc@ipb.csic.es

† Contributed equally

${ }^{1}$ Instituto de Parasitología y Biomedicina López-Neyra, IPBLN-CSIC, Avenida

del Conocimiento s/n, Granada, 18100, Spain

Full list of author information is available at the end of the article
}

The genetic component of SSc has been recently reinforced and several genes involved in immune regulation have been proposed as risk factors for the development of SSc [3]. A number of loci such as IRF5 [4], STAT4 [5,6], BANK1 [7,8], C8orf13-BLK [9,10], CD247 [11,12] and TNFSF4 $[13,14]$, have been associated with genetic predisposition to SSc in Caucasian populations. Some of these loci are shared with other autoimmune diseases, such as rheumatoid arthritis (RA) and systemic lupus erythematosus (SLE), reinforcing the theory of a common genetic background in autoimmune diseases [15].

CD226 (cluster of differentiation 226)/PTA1 (platelet and T-cell activation antigen 1)/DNAM-1 (DNAX accessory molecule 1 ) is a member of the immunoglobulin superfamily and it plays an important role in the co-

\section{Ciomed Central}


stimulation pathways of natural killer (NK) cells and activated T cells [16]. Furthermore, CD226 is constitutively expressed on NK cells, CD4+ and CD8+ T cells, monocytes, platelets and certain $\mathrm{B}$ cells playing a pleiotropic role in the immune system [16,17], thus subtle changes in CD226 expression could be involved in SSc immune imbalance.

CD226 gene polymorphisms have been correlated with an increasing number of autoimmune pathologies. Thus, the CD226 rs763361/Gly307Ser non-synonymous polymorphism was first correlated to type 1 diabetes susceptibility $[18,19]$, later to multiple autoimmune diseases $[19,20]$ and recently, to SSc [21]. Interestingly, the minor allele rs763361*T encodes a non-synonymous mutation (Gly307Ser) in the cytoplasmic tail of CD226 protein (exon 7). In addition, the rs763361 glycine to serine substitution could interfere in the phosphorylation of CD226 at 322Tyr and 329Ser residues, and the downstream signaling pathway may be modulated by these posttranslational modifications [16,22].

In a recent study performed in SLE, a three-variant haplotype in CD226 gene, comprising CD226 rs763361rs34794968-rs727088, was found to be associated with SLE and the authors proposed that rs727088 may be the single nucleotide polymorphism (SNP) with a functional influence on CD226 transcription levels [23].

The aim of this study was to test in a large European population the previously reported association of $C D 226$ gene rs763361/Gly307Ser with SSc, and to analyze, for the first time, the role of two additional polymorphisms, rs34794968 and rs727088, and the effect of CD226 rs763361-rs34794968-rs727088 haplotype in SSc.

\section{Materials and methods Subjects}

A total of 2,131 SSc cases and 3,966 controls from seven European Caucasian cohorts (Spain, Germany, the Netherlands, Italy, Sweden, the United Kingdom and Norway) were included in this study. Patients were diagnosed as having SSc using the criteria proposed by the $1980 \mathrm{ACR}$ and/or LeRoy and Medsger criteria $[24,25]$. In addition, patients were classified as having limited or diffuse SSc as defined by LeRoy et al. [26]. The following clinical data was collected for ascertainment of clinical phenotype of all the patients with SSc: age, gender, disease duration and presence of SSc-associated autoantibodies, ATA and ACA. Pulmonary fibrosis was diagnosed by High Resolution Computed Tomography (HRCT). Considering the previously reported subphenotype associations, the subtype, autoantibody status and pulmonary fibrosis data were available for all the patients included in this report (Table S1 in Additional file 1 shows these clinical data). The control population consisted of unrelated healthy individuals recruited in the same geographical regions as SSc patients and matched by age, sex and ethnicity with the SSc patients groups. Local ethical committees from all the participating centers approved the study. Both patients and controls were included in the study after written informed consent.

\section{CD226 genotyping and statistical analysis}

Three SNPs, rs763361 and rs3479968 located in exon 7, and rs727088 in the 3'UTR region were selected as genetic markers. The SNPs were analyzed by Taqman SNP genotyping assays in a $7900 \mathrm{HT}$ real-time polymerase chain reaction (PCR) System following the manufacturer's suggestions (Applied Biosystems, Foster City, CA, USA).

All cohorts were in Hardy-Weinberg equilibrium (HWE) at significance level $=0.01$ for all the included SNPs. PLINK (v1.07) software [27] was used for individual population association tests (significance was calculated by $2 \times 2$ contingency tables and Fisher's exact test or $\chi^{2}$ when necessary) and pooled analysis. Bonferroni and Benjamini and Hochberg false discovery rate method correction (FDR) were applied for multiple test correction [28]. In addition, the Breslow-Day test (BD test) was performed as implemented in PLINK to assess the homogeneity of the association among populations. Haplotype pooled analysis was performed by Haploview (Cambridge, MA, USA) and Statsdirect (Altrincham, Cheshire, UK) software. Power was calculated using the software Power Calculator for Genetic Studies 2006 and assuming an additive model [29].

\section{Results \\ CD226 rs763361/Gly307Ser, rs34794968 and rs727088 analysis}

Table 1 shows the genotype and allelic frequencies and pooled analyses of the three CD226 SNPs included in this report in the global disease and the considered subgroups. Tables S2 to S4 in Additional file 1 show the genotype and allele distribution of each of the tested variants in the seven analyzed European cohorts. The $\mathrm{BD}$ test revealed no statistically significant differences between the seven cohorts included, hence we performed a pooled analysis using the Mantel-Haenszel test under fixed effects for each of the tested polymorphisms. As opposed to Dieudé et al. [21], the pooled analysis of rs763361 showed no evidence of association with the whole set of SSc patients. Then, we interrogated the major SSc subphenotypes as defined by LeRoy et al. [26], and in addition by autoantibody status and by lung fibrosis as described in Dieudé et al.[21]. Allele frequencies in each subgroup were compared to control frequencies and no evidence of association was found at any of the considered subgroups. In addition, we 
Table 1 Genotype and allele distribution of CD226 rs763361 (chr:18, 65,682,622 bp), rs34794968 (chr:18; 65,682,006 bp), rs727088 (chr:18, 65,681,419 bp) genetic variants and pooled analysis.

\begin{tabular}{|c|c|c|c|c|c|c|c|c|c|}
\hline \multirow[b]{2}{*}{ SNP } & \multirow[b]{2}{*}{ Subgroup (N) } & \multicolumn{3}{|c|}{ Genotype, N (\%) } & \multirow[b]{2}{*}{ MAF (\%) } & \multicolumn{4}{|c|}{ Allele test } \\
\hline & & $1 / 1$ & $1 / 2$ & $2 / 2$ & & $P_{\mathrm{MH}}$ & $P_{\text {FDR_BH }}$ & OR [Cl 95\%] & $P_{\mathrm{BD}}$ \\
\hline \multirow[t]{7}{*}{ rs763361 } & Controls $(n=3811)$ & $906(23.77)$ & $1841(48.31)$ & $1064(27.92)$ & 47.93 & & & & \\
\hline & SSC $(n=2023)$ & $480(23.73)$ & $990(48.94)$ & $553(27.34)$ & 48.2 & 0.56 & 0.73 & $1.02[0.95-1.10]$ & 0.56 \\
\hline & ICSSc $(n=1397)$ & $332(23.77)$ & $681(48.75)$ & $384(27.49)$ & 48.14 & 0.64 & 0.95 & $1.02[0.94-1.11]$ & 0.8 \\
\hline & dcSSc $(n=626)$ & $148(23.64)$ & $309(49.36)$ & $169(27.00)$ & 48.32 & 0.6 & 0.94 & 1.03 [0.92-1.17] & 0.14 \\
\hline & $\mathrm{ACA}+(\mathrm{n}=797)$ & $176(22.08)$ & $396(49.69)$ & $225(28.23)$ & 46.93 & 0.68 & 0.68 & 0.98 [0.88-1.09] & 0.85 \\
\hline & ATA $+(n=503)$ & $133(26.44)$ & $239(47.51)$ & $131(26.04)$ & 50.2 & 0.22 & 0.28 & 1.09 [0.95-1.24] & 0.63 \\
\hline & $\mathrm{Fib}+(\mathrm{n}=729)$ & $176(24.14)$ & $359(49.25)$ & $194(26.61)$ & 48.77 & 0.48 & 0.58 & 1.04 [0.93-1.17] & 0.5 \\
\hline \multirow[t]{7}{*}{ rs34794968 } & Controls $(n=3858)$ & $669(17.34)$ & $1842(47.74)$ & $1347(34.91)$ & 41.21 & & & & \\
\hline & SSC $(n=2060)$ & $348(16.89)$ & $978(47.48)$ & $734(35.63)$ & 40.63 & 0.73 & 0.73 & 0.99 [0.91-1.07] & 0.37 \\
\hline & ICSSc $(n=1422)$ & $234(16.46)$ & $685(48.17)$ & $503(35.37)$ & 40.54 & 0.74 & 0.95 & 0.99 [0.90-1.08] & 0.71 \\
\hline & dcSSc $(n=638)$ & $114(17.87)$ & $293(45.92)$ & $231(36.21)$ & 40.83 & 0.94 & 0.94 & 1.00 [0.88-1.12] & 0.05 \\
\hline & $\mathrm{ACA}+(\mathrm{n}=816)$ & $129(15.81)$ & $390(47.79)$ & $297(36.40)$ & 39.71 & 0.35 & 0.68 & $0.95[0.85-1.06]$ & 0.6 \\
\hline & ATA+ $(n=518)$ & $100(19.31)$ & $249(48.07)$ & $169(32.63)$ & 43.34 & 0.28 & 0.28 & 1.08 [0.94-1.23] & 0.38 \\
\hline & $\mathrm{Fib}+(\mathrm{n}=755)$ & $122(16.16)$ & $362(47.95)$ & $271(35.89)$ & 40.13 & 0.58 & 0.58 & 0.97 [0.87-1.09] & 0.44 \\
\hline \multirow[t]{7}{*}{ rs727088 } & Controls $(n=3815)$ & $917(24.04)$ & $1869(48.99)$ & $1029(26.97)$ & 48.53 & & & & \\
\hline & SSC $(n=2042)$ & $489(23.95)$ & $1014(49.66)$ & $539(26.40)$ & 48.78 & 0.59 & 0.73 & $1.02[0.95-1.10]$ & 0.86 \\
\hline & ICSSc $(n=1409)$ & $336(23.85)$ & $702(49.82)$ & $371(26.33)$ & 48.76 & 0.63 & 0.95 & $1.02[0.94-1.11]$ & 0.66 \\
\hline & dcSSc $(n=633)$ & $153(24.17)$ & $312(49.29)$ & $168(26.54)$ & 48.82 & 0.71 & 0.94 & $1.02[0.91-1.15]$ & 0.26 \\
\hline & $A C A+(n=814)$ & $178(21.87)$ & $414(50.86)$ & $222(27.27)$ & 47.3 & 0.54 & 0.68 & 0.97 [0.87-1.08] & 0.56 \\
\hline & ATA+ $(n=514)$ & $138(26.85)$ & $250(48.64)$ & $126(24.51)$ & 51.17 & 0.14 & 0.28 & 1.10 [0.97-1.26] & 0.61 \\
\hline & $\mathrm{Fib}+(\mathrm{n}=739)$ & $185(25.03)$ & $363(49.12)$ & $191(25.85)$ & 49.59 & 0.4 & 0.58 & $1.05[0.94-1.17]$ & 0.86 \\
\hline
\end{tabular}

Controls are used as reference for all comparisons. ACA, anti-centromere antibodies; ATA, anti-topoisomerase antibodies; 95\% CI, 95\% confidence interval; dcSSc, diffuse cutaneous systemic sclerosis; Fib+, lung fibrosis positive SSc patients; IcSSc, limited cutaneous systemic sclerosis; MAF, minor allele frequency; NS, not significant; $\mathrm{OR}$, odds ratio; $P_{\mathrm{BD}}$, Breslow-Day homogeneity test $p$-value; $P_{\mathrm{FDR} \_\mathrm{BH}}$, corrected $P$-value using Benjamini and Hochberg false discovery rate; $P_{\mathrm{MH}}$, allelic Mantel-Haenszel fixed effects model $P$-value; SSc, systemic sclerosis.

observed no significant association in the pooled analyses of the CD226 rs34794968 and rs727088 genetic variants with neither the global disease nor with the considered phenotypic subgroups.

\section{CD226 haplotype block analysis}

Considering the CD226 haplotype block association described in SLE [23], we analyzed the possible effect of this haplotype block in SSc patients. In this analysis, considering only haplotypes with frequency $>5 \%$ in the pooled analysis, we reported no significant association with SSc susceptibility. However, stratification revealed that the TCG haplotype (SNP order: rs763361rs34794968- rs727088) was over-represented in the lung fibrosis positive subgroup of patients. This haplotype, composed of the minor alleles of rs763361 and rs727088 polymorphisms and the major allele of rs34794968, was not equivalent to that associated with SLE susceptibility, but showed a modest risk effect in the lung fibrosis positive group of patients. This association with lung fibrosis remained significant even after performing Bonferroni multiple test correction, $\left(P_{\text {Bonf }}=3.18 \mathrm{E}-02 \mathrm{OR}\right.$ 1.27 (1.05 to1.54), Table 2). Remarkably, a trend of association for the TCG haplotype was observed in the comparison between the lung fibrosis positive subset of patients and the fibrosis negative group of patients (Table 2). We consider that the lack of statistical significance may be possibly due to a reduced statistical power, as the lung fibrosis negative subgroup ( $n=$ $1,572)$ is smaller than the control group $(n=3,966)$.

\section{Discussion}

We carried out a well-powered case-control study aiming to test the contribution of three CD226 genetic variants (rs763361, rs34794968 and rs727088) to SSc susceptibility and clinical phenotypes. We report the association of a CD226 three-variant haplotype with SSc-related pulmonary fibrosis. However, we observed a lack of individual association of these three CD226 polymorphisms with SSc or with its serological and clinical manifestations.

The allele and genotype frequencies observed in our control group were similar to those described in the HapMap public database phase 3 (CEPH: Utah residents with ancestry from northern and western Europe; abbreviation: $\mathrm{CEU}$ ), and considerably comparable with those in Dieudé et al. report [21]. Although the present study did not confirm the previously reported association of 
Table 2 Association of CD226 haplotype block in the Fib+ subset of systemic sclerosis patients.

\begin{tabular}{|c|c|c|c|c|c|c|c|c|}
\hline rs763361 & rs34794968 & rs727088 & Subgroup & MAF (\%) & $P_{\mathrm{MH}}$ & $P_{\text {Bonf }}$ & OR [Cl 95\%] & $P_{\mathrm{BD}}$ \\
\hline & & & $\mathrm{Fib}+$ & 0.40 & & & & \\
\hline \multirow[t]{3}{*}{ T } & A & G & CTRL & 0.41 & 0.59 & NS & $0.97[0.86-1.08]$ & 0.45 \\
\hline & & & Fib- & 0.41 & 0.76 & NS & 0.98 [0.86-1.11] & 0.77 \\
\hline & & & $\mathrm{Fib}+$ & 0.10 & & & & \\
\hline \multirow[t]{3}{*}{ T } & C & G & CTRL & 0.08 & $1.59 \mathrm{E}-02$ & $3.18 \mathrm{E}-02$ & 1.27 [1.05-1.54] & 0.48 \\
\hline & & & Fib- & 0.08 & 0.069 & NS & 1.24 [0.99-1.56] & 0.51 \\
\hline & & & Fib+ & 0.50 & & & & \\
\hline \multirow[t]{2}{*}{ C } & C & A & CTRL & 0.51 & 0.44 & NS & $0.96[0.86-1.07]$ & 0.71 \\
\hline & & & Fib- & 0.51 & 0.50 & NS & 0.95 [0.84-1.09] & 0.44 \\
\hline
\end{tabular}

For the haplotype-specific analyses, the odds ratio (OR) with $95 \%$ confidence interval $(95 \% \mathrm{Cl}$ ) was determined for each allele variant in the haplotype tested against all of the others pooled together using the Mantel-Haenszel test under fixed effects model, considering no single reference haplotype. CTRL, healthy controls; Fib-, lung fibrosis negative SSC patients; Fib+, lung fibrosis positive SSC patients; MAF, minor allele frequency; $P_{\text {Bonf, }}$ corrected $P$-value using Bonferroni multiple test correction.

rs763361 with SSc, we found that one of the haplotypes containing the rs763361*T allele showed evidence of association with the lung fibrosis positive group of patients [21]. We consider that the lack of association for rs763361 individually could have arisen due to a type II error (false negative), because our sample size is similar to the study by Dieudé et al. and reaches $99 \%$ power to detect the previously reported effect of the polymorphism. It is worth mentioning that Dieudé et al. analyzed this polymorphism both in an Italian and German replication cohorts, the latest being the most associated with the FA+ group. Consequently our FA+ German cohort, in spite of being smaller than the one in Dieudé et al., showed the highest trend of association observed in this group (Table S1 in Additional file 1). Given the high power of our pooled analysis to detect similar associations to those reported in the previous SSc study, our data suggest that the previously reported effect for the association between CD226 rs763361*T allele and SSc susceptibility may be influenced by ethnical factors. Remarkably, Dieudé et al. studied the implication of the amino acid change encoded by rs763361*T in CD226 expression, but no significant differences were observed [21]. Our data together with SLE reports [23], suggest that haplotypic allele combinations might be considered for further functional studies.

Tao et al. described an increased susceptibility of NKT cells to apoptosis via CD95-CD95L or TCR-CD3 in NKT cells isolated from active SLE patients, and linked it with a deficient expression of CD226 [30]. Later, genetic studies revealed that rs727088 minor allele was part of a haplotype associated with SLE susceptibility and was responsible for a decrease in CD226 gene expression [23]. Despite experimental evidence of the role of rs727088 in CD226 transcription modulation in SLE, we detected no association signal of rs727088 or the SLE-risk haplotype with SSc susceptibility. These findings suggest that although $C D 226$ is a common risk factor for SLE and SSc, the genetic variants in this gene may have potentially divergent roles in both diseases or the causal variant might be disease specific. Noteworthy, it is well-established that SSc and SLE share a number of associated loci, but the associated variants are not necessarily the same, for example in the human leukocyte antigen (HLA) region [31]. Considering that fibrosis is a main hallmark of SSc, the specific association of CD226 with SSc fibrosis-positive patients might reflect the influence of this locus in diverse pathways. Interestingly, NLRP1 a common autoimmune disease risk factor has been reported to be associated with the ATA and lung fibrosis-positive subgroups of SSc patients [32]. Moreover, NLRP1 was reported to contribute to SLE in families suffering SLE and vitiligo or other autoimmune or autoinflammatory diseases [33] and it has been recently found to be associated with SLE in a Brazilian population [34]. Nevertheless, rs2670660 and an rs12150220-rs2670660 haplotype were the associated variants in SLE, but only rs8182352 was associated with SSc-related pulmonary fibrosis (although both rs12150220 and rs2670660 were analyzed) [32,34]. Hence, although the population size in the SLE study is limited, this differential association in SLE of a novel SSc fibrosis risk factor is analogous to the reported CD226 results.

It is well-established that SSc patients exhibit reduced numbers and impaired function of NKT cells [35-37] and the highest CD226 expression levels in healthy donors are found in NKT cells $[21,23]$. Thus, the impact of the associated CD226 haplotype reported in this study on the functions of SSc patients' NK and NKT cells should be further explored. Furthermore, new therapeutic approaches based on anti-CD226 mAb treatment have already been tested in autoimmunity animal models [38], and CD226 has been recently implied in novel $\mathrm{T}$ cell activation pathways [39] and NK-driven tissue injury in SLE patients [40]. Hence, the implication 
of CD226 in cell-mediated cytotoxicity should be considered. In addition, the possibility of lung fibrosis being a marker of generalized internal organ damage, which was not analyzed in this study and represented a limitation of our findings, should be interrogated.

To date just a few loci have been reported to be associated with SSc-related pulmonary involvement, such as IRF5 [6], STAT4 [6], TNFAIP3 [41], KCNA5 [42], NLRP1 [32] and HGF [43]. Hence, we consider that the confirmation of $C D 226$ as a pulmonary involvement marker might be valuable in the deciphering of the mechanisms that underlie the lung fibrosis process in SSc patients.

\section{Conclusions}

Our data suggest that previously autoimmune-associated CD226 gene polymorphisms play a role in the SSc pulmonary fibrosis events in European Caucasian populations, and confirm CD226 as an important shared autoimmune factor in SSc.

\section{Additional material}

Additional file 1: Population specific characteristics and genotype and allelic distribution of the three analyzed variants in each population. This file contains: Table S1 showing the population specific composition of the complete SSC set of patients for the analyzed features of the disease; Tables S2 to 4 showing the genotype and allele distributions of CD226 rs763361, rs34794968 and rs727088 genetic variants in seven European cohorts.

\section{Abbreviations}

ACA: anti-centromere autoantibodies; ATA: anti-topoisomerase antibodies; BD test: Breslow-Day test; CD226: cluster of differentiation 226; CEPH/CEU: Utah residents with ancestry from northern and western Europe; dcSSc: diffuse cutaneous systemic sclerosis; DNAM-1: DNAX accessory molecule 1; FDR: false discovery rate method correction; HLA: human leukocyte antigen; HRCT: high resolution computed tomography; HWE: Hardy-Weinberg equilibrium; ICSSc: limited cutaneous systemic sclerosis; PCR: polymerase chain reaction; PTA1: platelet and T-cell activation antigen 1; RA: rheumatoid arthritis; SLE: systemic lupus erythematosus; SNP: single nucleotide polymorphism; SSc: systemic sclerosis.

\section{Acknowledgements}

We thank Sofia Vargas, Sonia García and Gema Robledo for their excellent technical assistance and all the patients and control donors for their essential collaboration. We thank Banco Nacional de ADN (University of Salamanca, Spain) and the Norwegian Bone Marrow Donor Registry, who supplied part of the control DNA samples. We are also thankful to EUSTAR (the EULAR Scleroderma Trials and Research group) and the German Network of Systemic Sclerosis for the facilitation of this project. This work was supported by the following grants: JM was funded by GENFER from the Spanish Society of Rheumatology, SAF2009-11110 from the Spanish Ministry of Science, CTS-4977 from Junta de Andalucía, Spain, in part by Redes Temáticas de Investigación Cooperativa Sanitaria Program, RD08/ 0075 (RIER) from Instituto de Salud Carlos III (ISCIII), Spain and by Fondo Europeo de Desarrollo Regional (FEDER). TRDJR was funded by the VIDI laureate from the Dutch Association of Research (NWO) and Dutch Arthritis Foundation (National Reumafonds). JM and TRDJR were sponsored by the Orphan Disease Program grant from the European League Against Rheumatism (EULAR). BPCK is supported by the Dutch Diabetes Research
Foundation (grant 2008.40.001) and the Dutch Arthritis Foundation (Reumafonds, grant NR 09-1-408). TW was granted by DFG WI 1031/6.1. This study was also funded by PI-0590-2010, Consejería de Salud, Junta de Andalucía, Spain.

The Spanish Scleroderma Group: Norberto Ortego-Centeno and Jose Luis Callejas, Unidad de Enfermedades Sistémicas Autoinmunes, Servicio de Medicina Interna, Hospital Clínico Universitario San Cecilio, Granada; Nuria Navarrete, Servicio de Medicina Interna, Hospital Virgen de las Nieves, Granada; Rosa García Portales, Servicio de Reumatología, Hospital Virgen de la Victoria, Málaga; Antonio Fernández-Nebro, Servicio de Reumatología, Hospital Carlos Haya, Málaga; María F. González-Escribano, Servicio de Inmunología, Hospital Virgen del Rocío, Sevilla; Julio Sánchez-Román and Francisco José García-Hernández, Servicio de Medicina Interna, Hospital Virgen del Rocío, Sevilla; Ma Ángeles Aguirre and Inmaculada Gómez-Gracia, Servicio de Reumatología, Hospital Reina Sofía, Córdoba; Benjamín Fernández-Gutiérrez and Luis Rodríguez-Rodríguez, Servicio de Reumatología, Hospital Clínico San Carlos, Madrid; José Luis Andreu and Mónica Fernández de Castro, Servicio de Reumatología, Hospital Puerta del Hierro, Madrid; Paloma García de la Peña, Servicio de Reumatología, Hospital Madrid Norte Sanchinarro, Madrid; Francisco Javier López-Longo and Lina Martínez, Servicio de Reumatología, Hospital General Universitario Gregorio Marañón, Madrid; Vicente Fonollosa, Servicio de Medicina Interna, Hospital Valle de Hebrón, Barcelona; Iván Castellví, Servicio de Reumatología, Hospital Sant Pau, Barcelona; Anna Pros, Servicio de Reumatología, Hospital Del Mar, Barcelona; Mónica Rodríguez Carballeira, Servicio de Medicina Interna, Hospital Universitari Mútua Terrasa, Barcelona; Bernardino Díaz, Luis Trapiella and María Gallego, Servicio de Medicina Interna, Hospital Central de Asturias, Oviedo; Inés Vaqueiro, Unidad de Trombosis y Vasculitis, Servicio de Medicina Interna, Hospital Xeral-Complexo Hospitalario Universitario de Vigo, Vigo; María Victoria Egurbide, Servicio de Medicina Interna, Hospital de Cruces, Barakaldo; Luis Sáez-Comet, Unidad de Enfermedades Autoinmunes Sistémicas, Servicio de Medicina Interna, Hospital Universitario Miguel Servet, Zaragoza; Federico Díaz and Vanesa Hernández, Servicio de Reumatología, Hospital Universitario de Canarias, Tenerife; José Andrés Román-Ivorra, Servicio de Reumatología, Hospital Universitari i Politecnic La Fe, Valencia.

\section{Author details}

${ }^{1}$ Instituto de Parasitología y Biomedicina López-Neyra, IPBLN-CSIC, Avenida del Conocimiento s/n, Granada, 18100, Spain. ${ }^{2}$ Servicio de Medicina Interna, Hospital Valle de Hebron, Passeig de la Vall d'Hebron, 119-129, Barcelona, 08035, Spain. ${ }^{3}$ RCCS Fondazione Policlinico-Mangiagalli-Regina Elena and University of Milan, Allergy, Clinical Immunology and Rheumatology, Via Francesco Sforza 28, Milan, 20122, Italy. ${ }^{4}$ Department of Rheumatology, Radboud University Nijmegen Medical Centre, Geert Grooteplein Zuid 10, Nijmegen, 6525 GA, The Netherlands. ${ }^{5}$ Servicio de Medicina Interna, Hospital Clínico Universitario, Avenida Doctor Olóriz 16, Granada, 18012, Spain. ${ }^{6}$ Servicio de Enfermedades Autoinmunes, Hospital Clinic, CNillarroel, 170, Barcelona, 08036, Spain. ${ }^{7}$ Servicio de Reumatología, Hospital 12 de Octubre, Avenida de Córdoba, s/n, Madrid, 28041, Spain. ${ }^{8}$ Servicio de Medicina Interna, Hospital Carlos Haya, Avenida Carlos Haya s/n, Málaga, 29010, Spain. ${ }^{9}$ Servicio de Medicina Interna, Hospital Virgen del Rocío, Avenida Manuel Siurot s/n, Sevilla, 41013, Spain. ${ }^{10}$ Servicio de Reumatología, Hospital Universitario Marqués de Valdecilla, IFIMAV, Avenida Valdecilla 25, Santander, 39008, Spain. ${ }^{11}$ Servicio de Reumatología, Hospital del Doctor Peset Aleixandre, Avenida Gaspar Aguilar 90, Valencia, 46017, Spain. ${ }^{12}$ Unidad Trombosis y Vasculitis, Servicio de Medicina Interna, Hospital Xeral-Complexo Hospitalario Universitario de Vigo, Rua Pizarro 22, Vigo, 36204, Spain. ${ }^{13}$ Servicio de Reumatología, Hospital Universitario de Bellvitge, C/Feixa Llarga $s / n, 08907$, Barcelona, Spain. ${ }^{14}$ Servicio de Medicina Interna, Hospital Parc Taulí, Parc del Taulí s/n, Sabadell, 08208, Spain. ${ }^{15}$ Hannover Medical School, Carl-Neuberg-Straße 1, Hannover, 30625, Germany. ${ }^{16}$ Ruhr University of Bochum, Universitätsstraße 150, Bochum, 44801, Germany. ${ }^{17}$ Department of Rheumatology, Leiden University Medical Center, Albinusdreef 2, Leiden, 2333 ZA, The Netherlands. ${ }^{18}$ Department of Rheumatology, Rikshospitalet, Oslo University Hospital, Rikshospitalet-Radiumhospitalet Medical Center, Oslo, 0027, Norway. ${ }^{19}$ Department of Rheumatology, Lund University, Paradisgatan 2, Lund, SE-221 00, Sweden. ${ }^{20}$ Department of Medicine, Università degli Studi di Verona, Via dell'Artigliere, 19, Verona 37129, Italy. ${ }^{21}$ Institute of Cellular Medicine, Newcastle University, Framlington Place, Newcastle upon Tyne, Newcastle, NE2 4HH, UK. ${ }^{22}$ Centre for Rheumatic Diseases, Glasgow Royal Infirmary, 84 Castle Street, Glasgow G4 OSF, UK. 
${ }^{23}$ Arthritis Research UK Epidemiology Unit, The University of Manchester, Manchester Academic Health Science Centre, Stopford Building, Oxford Road, Manchester, M13 9PT, UK. ${ }^{24}$ Section Complex Genetics, Department of Medical Genetics, University Medical Center Utrecht, Universiteitsweg 100, Utrecht, 3584 CG, The Netherlands. ${ }^{25}$ Centre for Rheumatology, Royal Free and University College Medical School, University College London, Royal Free Campus, Rowland Hill Street, London, NW3 PF, UK. ${ }^{26}$ Department of Rheumatology and Clinical Immunology, University Medical Center Utrecht, Heidelberglaan 100, Utrecht, 3584 CX, The Netherlands.

\section{Authors' contributions}

LBC has contributed to the analysis and interpretation of data and to the drafting the manuscript. CPS, LB and JCB have participated in the acquisition of data and the drafting of the manuscript. CF, TRDJR and JM contributed to the conception and design of the study and have critically revised the manuscript. MCV, RRF, GE, PC, MTC, MJC, MAGG, EB, MCF, JN, CT, TW, AK, AJS, AMHV, RH, CL, JMVL, MMC, AH, CPD, BPK have been involved in the acquisition of data and the revision of the manuscript. All authors read and approved the final manuscript.

\section{Competing interests}

The authors declare that they have no competing interests.

Received: 9 January 2012 Revised: 27 March 2012

Accepted: 24 April 2012 Published: 24 April 2012

\section{References}

1. Gabrielli A, Avvedimento EV, Krieg T: Scleroderma. N Engl J Med 2009, 360:1989-2003.

2. Steen VD: The many faces of scleroderma. Rheum Dis Clin North Am 2008, 34:1-15, v.

3. Martin J, Fonseca C: The genetics of scleroderma. Curr Rheumatol Rep 2011, 13:13-20.

4. Dieude P, Guedj M, Wipff J, Avouac J, Fajardy I, Diot E, Granel B, Sibilia J, Cabane J, Mouthon L, Cracowski JL, Carpentier PH, Hachulla E, Meyer O, Kahan A, Boileau C, Allanore Y: Association between the IRF5 rs2004640 functional polymorphism and systemic sclerosis: a new perspective for pulmonary fibrosis. Arthritis Rheum 2009, 60:225-233.

5. Rueda B, Broen J, Simeon C, Hesselstrand R, Diaz B, Suarez H, OrtegoCenteno N, Riemekasten G, Fonollosa V, Vonk MC, van den Hoogen FH, Sanchez-Roman J, Aguirre-Zamorano MA, Garcia-Portales R, Pros A, Camps MT, Gonzalez-Gay MA, Coenen MJ, Airo P, Beretta L, Scorza R, van Laar J, Gonzalez-Escribano MF, Nelson JL, Radstake TR, Martin J: The STAT4 gene influences the genetic predisposition to systemic sclerosis phenotype. Hum Mol Genet 2009, 18:2071-2077.

6. Dieude P, Guedj M, Wipff J, Ruiz B, Hachulla E, Diot E, Granel B, Sibilia J, Tiev K, Mouthon L, Cracowski JL, Carpentier PH, Amoura Z, Fajardy I, Avouac J, Meyer O, Kahan A, Boileau C, Allanore Y: STAT4 is a genetic risk factor for systemic sclerosis having additive effects with IRF5 on disease susceptibility and related pulmonary fibrosis. Arthritis Rheum 2009, 60:2472-2479.

7. Dieude P, Wipff J, Guedj M, Ruiz B, Melchers I, Hachulla E, Riemekasten G, Diot E, Hunzelmann N, Sibilia J, Tiev K, Mouthon L, Cracowski JL, Carpentier PH, Distler J, Amoura Z, Tarner I, Avouac J, Meyer O, Kahan A, Boileau C, Allanore Y: BANK1 is a genetic risk factor for diffuse cutaneous systemic sclerosis and has additive effects with IRF5 and STAT4. Arthritis Rheum 2009, 60:3447-3454.

8. Rueda B, Gourh P, Broen J, Agarwal SK, Simeon C, Ortego-Centeno N, Vonk MC, Coenen M, Riemekasten G, Hunzelmann N, Hesselstrand R, Tan FK, Reveille JD, Assassi S, Garcia-Hernandez FJ, Carreira P, Camps M, Fernandez-Nebro A, Garcia de la Pena P, Nearney T, Hilda D, GonzalezGay MA, Airo P, Beretta L, Scorza R, Radstake TR, Mayes MD, Arnett FC, Martin J: BANK1 functional variants are associated with susceptibility to diffuse systemic sclerosis in Caucasians. Ann Rheum Dis 2010, 69:700-705.

9. Gourh P, Agarwal SK, Martin E, Divecha D, Rueda B, Bunting H, Assassi S, Paz G, Shete S, McNearney T, Draeger H, Reveille JD, Radstake TR, Simeon CP, Rodriguez L, Vicente E, Gonzalez-Gay MA, Mayes MD, Tan FK, Martin J, Arnett FC: Association of the C8orf13-BLK region with systemic sclerosis in North-American and European populations. J Autoimmun 2010, 34:155-162.
10. Coustet B, Dieude P, Guedj M, Bouaziz M, Avouac J, Ruiz B, Hachulla E, Diot E, Kracowski JL, Tiev K, Sibilia J, Mouthon L, Frances C, Amoura Z, Carpentier P, Cosnes A, Meyer O, Kahan A, Boileau C, Chiocchia G, Allanore $Y$ : C8orf 13/BLK is a genetic risk locus for systemic sclerosis and has additive effect with BANK1: Results from a large French cohort and meta-analysis. Arthritis Rheum 2011, 63:2091-2096.

11. Radstake TR, Gorlova O, Rueda B, Martin JE, Alizadeh BZ, PalominoMorales R, Coenen MJ, Vonk MC, Voskuyl AE, Schuerwegh AJ, Broen JC, van Riel PL, van 't Slot R, Italiaander A, Ophoff RA, Riemekasten G, Hunzelmann N, Simeon CP, Ortego-Centeno N, Gonzalez-Gay MA, Gonzalez-Escribano MF, Airo P, van Laar J, Herrick A, Worthington J, Hesselstrand R, Smith V, de Keyser F, Houssiau F, Chee MM, et al: Genomewide association study of systemic sclerosis identifies CD247 as a new susceptibility locus. Nat Genet 2010, 42:426-429.

12. Dieude P, Boileau C, Guedj M, Avouac J, Ruiz B, Hachulla E, Diot E, Cracowski JL, Tiev K, Sibilia J, Mouthon L, Frances C, Amoura Z, Carpentier P, Cosnes A, Meyer O, Kahan A, Chiocchia G, Allanore Y: Independent replication establishes the CD247 gene as a genetic systemic sclerosis susceptibility factor. Ann Rheum Dis 2011, 70:1695-1696.

13. Gourh P, Arnett FC, Tan FK, Assassi S, Divecha D, Paz G, McNearney T, Draeger H, Reveille JD, Mayes MD, Agarwal SK: Association of TNFSF4 (OX40L) polymorphisms with susceptibility to systemic sclerosis. Ann Rheum Dis 2010, 69:550-555.

14. Bossini-Castillo L, Broen JC, Simeon CP, Beretta L, Vonk MC, OrtegoCenteno N, Espinosa G, Carreira P, Camps MT, Navarrete N, GonzalezEscribano MF, Vicente-Rabaneda E, Rodriguez L, Tolosa C, Roman-Ivorra JA, Gomez-Gracia I, Garcia-Hernandez FJ, Castellvi I, Gallego M, FernandezNebro A, Garcia-Portales R, Egurbide MV, Fonollosa V, de la Pena PG, Pros A, Gonzalez-Gay MA, Hesselstrand R, Riemekasten G, Witte T, Coenen MJ, et al: A replication study confirms the association of TNFSF4 (OX40L) polymorphisms with systemic sclerosis in a large European cohort. Ann Rheum Dis 2011, 70:638-641.

15. Zhernakova A, van Diemen CC, Wijmenga C: Detecting shared pathogenesis from the shared genetics of immune-related diseases. Nat Rev Genet 2009, 10:43-55.

16. $\mathrm{Xu} Z$, Jin B: A novel interface consisting of homologous immunoglobulin superfamily members with multiple functions. Cell Mol Immunol 2010, 7:11-19.

17. Maier LM, Hafler DA: Autoimmunity risk alleles in costimulation pathways. Immunol Rev 2009, 229:322-336.

18. Todd JA, Walker NM, Cooper JD, Smyth DJ, Downes K, Plagnol V, Bailey R, Nejentsev S, Field SF, Payne F, Lowe CE, Szeszko JS, Hafler JP, Zeitels L, Yang JH, Vella A, Nutland S, Stevens HE, Schuilenburg H, Coleman G, Maisuria M, Meadows W, Smink L, Healy B, Burren OS, Lam AA, Ovington NR, Allen J, Adlem E, Leung HT, et al: Robust associations of four new chromosome regions from genome-wide analyses of type 1 diabetes. Nat Genet 2007, 39:857-864.

19. Hafler JP, Maier LM, Cooper JD, Plagnol V, Hinks A, Simmonds MJ, Stevens HE, Walker NM, Healy B, Howson JM, Maisuria M, Duley S, Coleman G, Gough SC, Worthington J, Kuchroo VK, Wicker LS, Todd JA: CD226 Gly307Ser association with multiple autoimmune diseases. Genes Immun 2009, 10:5-10.

20. Maiti AK, Kim-Howard X, Viswanathan P, Guillen L, Qian X, Rojas-Villarraga A, Sun C, Canas C, Tobon GJ, Matsuda K, Shen N, Chernavsky AC, Anaya JM, Nath SK: Non-synonymous variant (Gly307Ser) in CD226 is associated with susceptibility to multiple autoimmune diseases. Rheumatology (Oxford) 2010, 49:1239-1244.

21. Dieude P, Guedj M, Truchetet ME, Wipff J, Revillod L, Riemekasten G, Matucci-Cerinic M, Melchers I, Hachulla E, Airo P, Diot E, Hunzelmann N, Mouthon L, Cabane J, Cracowski JL, Riccieri V, Distler J, Amoura Z, Valentini G, Camaraschi P, Tarner I, Frances C, Carpentier P, Brembilla NC, Meyer O, Kahan A, Chizzolini C, Boileau C, Allanore Y: Association of the CD226 307Ser variant with systemic sclerosis: Evidence for a contribution of co-stimulation pathways in SSc pathogenesis. Arthritis Rheum 2011, 63:1097-1105.

22. Shibuya K, Lanier LL, Phillips JH, Ochs HD, Shimizu K, Nakayama E, Nakauchi $H$, Shibuya A: Physical and functional association of LFA-1 with DNAM-1 adhesion molecule. Immunity 1999, 11:615-623.

23. Lofgren SE, Delgado-Vega AM, Gallant CJ, Sanchez E, Frostegard J, Truedsson L, de Ramon Garrido E, Sabio JM, Gonzalez-Escribano MF, PonsEstel BA, D'Alfonso S, Witte T, Lauwerys BR, Endreffy E, Kovacs L, 
Vasconcelos C, Martins da Silva B, Martin J, Alarcon-Riquelme ME, Kozyrev SV: A 3'-untranslated region variant is associated with impaired expression of CD226 in T and natural killer T cells and is associated with susceptibility to systemic lupus erythematosus. Arthritis Rheum 2010, 62:3404-3414.

24. Preliminary criteria for the classification of systemic sclerosis (scleroderma). Subcommittee for scleroderma criteria of the American Rheumatism Association Diagnostic and Therapeutic Criteria Committee. Arthritis Rheum 1980, 23:581-590.

25. LeRoy EC, Medsger TA Jr: Criteria for the classification of early systemic sclerosis. J Rheumatol 2001, 28:1573-1576.

26. LeRoy EC, Black C, Fleischmajer R, Jablonska S, Krieg T, Medsger TA, Rowell N, Wollheim F: Scleroderma (systemic sclerosis): classification, subsets and pathogenesis. J Rheumatol 1988, 15:202-205.

27. Purcell $S$, Neale B, Todd-Brown $K$, Thomas L, Ferreira MA, Bender D, Maller J, Sklar P, de Bakker PI, Daly MJ, Sham PC: PLINK: a tool set for wholegenome association and population-based linkage analyses. Am J Hum Genet 2007, 81:559-575.

28. Benjamini $Y$, Hochberg $Y$ : Controlling the false discovery rate: a practical and powerful approach to multiple testing. J R Statist Soc B 1995, 57:289-300

29. Skol AD, Scott $L$, Abecasis GR, Boehnke M: Joint analysis is more efficient than replication-based analysis for two-stage genome-wide association studies. Nat Genet 2006, 38:209-213.

30. Tao D, Shangwu L, Qun W, Yan L, Wei J, Junyan L, Feili G, Boquan J, Jinquan T: CD226 expression deficiency causes high sensitivity to apoptosis in NK T cells from patients with systemic lupus erythematosus. J Immunol 2005, 174:1281-1290.

31. Martin JE, Bossini-Castillo L, Martin J: Unraveling the genetic component of systemic sclerosis. Hum Genet 2012.

32. Dieude P, Guedj M, Wipff J, Ruiz B, Riemekasten G, Airo P, Melchers I, Hachulla E, Cerinic MM, Diot E, Hunzelmann N, Caramaschi P, Sibilia J, Tiev K, Mouthon L, Riccieri V, Cracowski JL, Carpentier PH, Distler J, Amoura Z, Tarner I, Avouac J, Meyer O, Kahan A, Boileau C, Allanore Y: NLRP1 influences the systemic sclerosis phenotype: a new clue for the contribution of innate immunity in systemic sclerosis-related fibrosing alveolitis pathogenesis. Ann Rheum Dis 2011, 70:668-674.

33. Jin Y, Mailloux CM, Gowan K, Riccardi SL, LaBerge G, Bennett DC, Fain PR, Spritz RA: NALP1 in vitiligo-associated multiple autoimmune disease. N Engl J Med 2007, 356:1216-1225.

34. Pontillo A, Girardelli M, Kamada AJ, Pancotto JA, Donadi EA, Crovella S, Sandrin-Garcia P: Polimorphisms in Inflammasome Genes Are Involved in the Predisposition to Systemic Lupus Erythematosus. Autoimmunity 2012.

35. Riccieri V, Parisi G, Spadaro A, Scrivo R, Barone F, Moretti T, Bernardini G, Strom R, Taccari E, Valesini G: Reduced circulating natural killer T cells and gamma/delta T cells in patients with systemic sclerosis. J Rheumatol 2005, 32:283-286.

36. Kojo S, Adachi Y, Keino H, Taniguchi M, Sumida T: Dysfunction of $T$ cell receptor AV24AJ18+, BV11+ double-negative regulatory natural killer $\mathrm{T}$ cells in autoimmune diseases. Arthritis Rheum 2001, 44:1127-1138.

37. Mitsuo A, Morimoto S, Nakiri Y, Suzuki J, Kaneko H, Tokano Y, Tsuda H, Takasaki Y, Hashimoto H: Decreased CD161+CD8+ T cells in the peripheral blood of patients suffering from rheumatic diseases. Rheumatology (Oxford) 2006, 45:1477-1484.

38. Dardalhon V, Schubart AS, Reddy J, Meyers JH, Monney L, Sabatos CA, Ahuja R, Nguyen K, Freeman GJ, Greenfield EA, Sobel RA, Kuchroo VK: CD226 is specifically expressed on the surface of Th1 cells and regulates their expansion and effector functions. J Immunol 2005, 175:1558-1565.

39. Joller N, Hafler JP, Brynedal B, Kassam N, Spoerl S, Levin SD, Sharpe AH, Kuchroo VK: Cutting edge: TIGIT has T cell-intrinsic inhibitory functions. J Immunol 2011, 186:1338-1342.

40. Huang Z, Fu B, Zheng SG, Li X, Sun R, Tian Z, Wei H: Involvement of CD226+ NK cells in immunopathogenesis of systemic lupus erythematosus. J Immunol 2011, 186:3421-3431.

41. Dieude P, Guedj M, Wipff J, Ruiz B, Riemekasten G, Matucci-Cerinic M, Melchers I, Hachulla E, Airo P, Diot E, Hunzelmann N, Cabane J, Mouthon L, Cracowski JL, Riccieri V, Distler J, Meyer O, Kahan A, Boileau C, Allanore Y: Association of the TNFAIP3 rs5029939 variant with systemic sclerosis in the European Caucasian population. Ann Rheum Dis 2010, 69:1958-1964.

42. Wipff J, Dieude P, Guedj M, Ruiz B, Riemekasten G, Cracowski JL, MatucciCerinic M, Melchers I, Humbert M, Hachulla E, Airo P, Diot E, Hunzelmann N,
Caramaschi P, Sibilia J, Valentini G, Tiev K, Girerd B, Mouthon L, Riccieri V, Carpentier PH, Distler J, Amoura Z, Tarner I, Degano B, Avouac J, Meyer O, Kahan A, Boileau C, Allanore Y: Association of a KCNA5 gene polymorphism with systemic sclerosis-associated pulmonary arterial hypertension in the European Caucasian population. Arthritis Rheum 2010, 62:3093-3100.

43. Hoshino K, Satoh T, Kawaguchi Y, Kuwana M: Association of hepatocyte growth factor promoter polymorphism with severity of interstitial lung disease in Japanese patients with systemic sclerosis. Arthritis Rheum 2011, 63:2465-2472.

doi:10.1186/ar3809

Cite this article as: Bossini-Castillo et al: A multicenter study confirms CD226 gene association with systemic sclerosis-related pulmonary fibrosis. Arthritis Research \& Therapy 2012 14:R85.

\section{Submit your next manuscript to BioMed Central and take full advantage of:}

- Convenient online submission

- Thorough peer review

- No space constraints or color figure charges

- Immediate publication on acceptance

- Inclusion in PubMed, CAS, Scopus and Google Scholar

- Research which is freely available for redistribution

Submit your manuscript at www.biomedcentral.com/submit
C Biomed Central 